\title{
Short-Term Weight Changes in Treated Primary Hypothyroid Subjects
}

\author{
Abul Kalam Mohammad Aminul Islam , Abul Bashar Mohammad Kamrul Hasan 2, *, \\ Moinul Islam ${ }^{3}$, Mohammad Asaduzzaman ${ }^{4}$, Mohammad Rafiq Uddin ${ }^{5}$, Shiropa Islam ${ }^{6}$, \\ Mohammed Fariduddin ${ }^{7}$
}

${ }^{1}$ Department of Endocrinology, Colonel Abdul Malek Medical College, Manikganj, Bangladesh

${ }^{2}$ Department of Endocrinology, Mymensingh Medical College Hospital, Mymensingh, Bangladesh

${ }^{3}$ Department of Endocrinology, Dhaka Medical College Hospital, Dhaka, Bangladesh

${ }^{4}$ Medicine Outpatient Department, Shaheed Sheikh Abu Naser Specialized Hospital, Khulna, Bangladesh

${ }^{5}$ Department of Endocrinology, Chittagong Medical College Hospital, Chittagong, Bangladesh

${ }^{6}$ Department of Dermatology, Kurmitola General Hospital, Dhaka, Bangladesh

${ }^{7}$ Department of Endocrinology, Bangabandhu Sheikh Mujib Medical University, Dhaka, Bangladesh

\section{Email address:}

aminu173@yahoo.com (A. K. M. A. Islam), rangassmc@gmail.com (A. B. M. K. Hasan), dr.moinulsb28th@gmail.com (M. Islam), asaduzzmn@gmail.com (M. Asaduzzaman),rafiq14@gmail.com (M. R. Uddin), shiropasbme@gmail.com (S. Islam),

dr.md.fariduddin@gmail.com (M. Fariduddin)

${ }^{*}$ Corresponding author

\section{To cite this article:}

Abul Kalam Mohammad Aminul Islam, Abul Bashar Mohammad Kamrul Hasan, Moinul Islam, Mohammad Asaduzzaman, Mohammad Rafiq Uddin, Shiropa Islam, Mohammed Fariduddin. Short-Term Weight Changes in Treated Primary Hypothyroid Subjects. International Journal of Diabetes and Endocrinology. Vol. 4, No. 1, 2019, pp. 1-5. doi: 10.11648/j.ijde.20190401.11

Received: December 15, 2018; Accepted: December 28, 2018; Published: January 29, 2019

\begin{abstract}
Weight loss due to diuresis is an early clinical response of treatment with levothyroxine in primary hypothyroidism. The objective of this study was to evaluate weight changes in patients with primary hypothyroidism after 6 weeks of initiation of treatment with levothyroxine. This prospective observational follow up study included 99 newly diagnosed primary hypothyroid patients of 18-60 years of age of both sexes. The weight and height of each patient were measured and body mass index (BMI) was calculated both at the time of enrollment and at the end of 6 weeks of treatment with levothyroxine, and variables at the baseline and at follow up were compared. 93 patients out of 99 completed follow-up at $6 \pm 1$ weeks. There were significant reduction in TSH level $(85.1 \pm 51.6$ vs. $1.87 \pm 0.9 \mu \mathrm{IU} / \mathrm{mL}$, mean \pm SD) and increase in FT4 level $(0.49 \pm 0.19$ vs. $1.4 \pm 0.78 \mathrm{ng} / \mathrm{dL}$, mean $\pm \mathrm{SD})$ at follow up in comparison to their baseline values. Among the participants, $90.3 \%$ lost body weight while $5.4 \%$ gained weight and $4.3 \%$ of subjects didn't show any change in their weight at the end of the study. The mean body weight and mean BMI after levothyroxine replacement were significantly lower (weight $62.2 \pm 13.7$ vs. $59.0 \pm 12.1 \mathrm{~kg}$, BMI $25.1 \pm 4.6$ vs. $23.8 \pm 4.1 \mathrm{Kg} / \mathrm{M}^{2}$, mean $\pm \mathrm{SD}$ ) than the pretreatment values. The mean changes in body weight and BMI were $3.19 \pm 0.32 \mathrm{Kg}($ mean $\pm \mathrm{SEM})$ and $1.31 \pm 0.14 \mathrm{Kg} / \mathrm{M}^{2}$ (mean $\pm \mathrm{SEM}$ ) respectively. The mean changes in body weight and BMI did not differ significantly among subjects with different TSH categories. No statistically significant effect of any individual predictors like age, gender, and socioeconomic status, weight at baseline, baseline TSH, baseline FT4 and presence of thyroid autoimmunity was observed on weight change. Levothyroxine replacement was associated with a significant reduction of mean body weight and BMI at short-term follow up in our study, though not all patients experienced weight loss.
\end{abstract}

Keywords: Body Weight, Body Mass Index, Primary Hypothyroidism, Levothyroxine Replacement 


\section{Introduction}

The clinical spectrum of primary hypothyroidism is broad; the common presenting features of moderate to severe hypothyroidism include easy fatigability, cold intolerance, weight gain, constipation, menstrual abnormality especially menorrhagia and muscle cramps. Physical findings may include a cool, rough, dry skin; puffy face and hands; a hoarse, husky voice; and slow reflexes. These symptoms are non-specific and may present in euthyroid subjects and the diagnosis of hypothyroidism must be made biochemically measuring thyroid stimulating hormone (TSH) and free T4 (FT4) level in the blood sample [1]. The prevalence of overt hypothyroidism in the developed world is about $4-5 \%$, though a higher prevalence was observed in India [2-5].

Mainstay of treatment of hypothyroidism is levothyroxine. The typical oral dose of levothyroxine is approximately 1.6 to $1.8 \mu \mathrm{g}$ per $\mathrm{kg}$ of ideal body weight per day. Thyroxine has a 7-day half-life and approximately 6 weeks is required before there is complete equilibration of the FT4 and biologic effects of levothyroxine. Accordingly, with rare exception like pregnancy, assessment of a given dose should not be made until 6 weeks have passed [6-7].

An early clinical response to levothyroxine replacement is diuresis of 2 to $4 \mathrm{~kg}$. Excretion of excess body water associated with myxedema is thought to be the predominant mechanism of weight loss after treatment of hypothyroidism. Thereafter pulse rate and pulse pressure increase, appetite improves and constipation may disappear. Hoarseness abates slowly, and changes in skin and hair do not disappear for several months. A substantial time lag is required for the assessment of response to treatment [8].

The present study assessed weight change in response to levothyroxine replacement. The assessment was made measuring the weights of the primary hypothyroid patients at the start and 6 weeks after initiation of treatment.

\section{Materials and Methods}

This observational follow-up study was carried out at the Endocrinology Outpatient Department of Bangabandhu Sheikh Mujib Medical University, Dhaka, Bangladesh from May 2014 to April 2015. The research protocol was approved by the Institutional Review Board (IRB) of the institute. The study enrolled 99 newly diagnosed primary hypothyroid patients of both sexes aging 18-60 years. Serum TSH and FT4 were measured by Chemiluminescent sequential immunometric assay with the IMMULITE 2000 system analyzers (Siemens diagnostic). Patients having a low FT4 level $(<0.8 \mathrm{ng} / \mathrm{dL})$ and high TSH level $(>5.50 \mathrm{mIU} / \mathrm{L})$, according to the laboratory's normal reference range, were considered to have primary hypothyroidism. Patients with other acute and chronic illness, who are recovering from an acute illness, with history of neck irradiation and thyroid surgery, who are receiving iodinecontaining drugs such as lithium and amiodarone, who are already receiving treatment for hypothyroidism, who are adopting lifestyle measures or taking medication for weight reduction, and pregnant \& lactating women were excluded. Written informed consent was taken from subjects after complete explanation of the procedure and objectives of this study. All patients were interviewed by using a semi-structured data collection sheet. Demographic data like age, gender, occupation and socioeconomic status were recorded. The weight and height of each patient were measured using standard weighing scale and height scale respectively and body mass index (BMI) was calculated at the time of enrolment and at the end of 6 weeks of treatment with levothyroxine and were recorded. Levothyroxine dose for each patient was calculated using the ideal body weight for each patient rather than the actual body weight. The ideal body weight of each patient was calculated using the formula $22 \times$ height in $\mathrm{m}^{2}$ for men and $21 \times$ height in $\mathrm{m}^{2}$ for women. Each subject was prescribed with the levothyroxine tablet at a standard dose of $1.6-1.8 \mu \mathrm{g} / \mathrm{kg}$ body weight per day to take in empty stomach at least one hour before breakfast; tablets from the same manufacturer were ensured for each patient. For the convenience of the patient, the dose was approximated to the next half of a 50 microgram tablet. The patients were followed up after the $6 \pm 1$ week of initiation of treatment for evaluation of weight and BMI changes. A total of 93 patients attended the last follow up and 6 were dropped out of the study. At follow-up, the weight and height of each patient were measured using the same weighing scale and height scale used at initial measurement and BMI was calculated. All information and records were anonymous and kept confidential to the investigators.

Statistical analysis: Statistical analysis was done using IBM SPSS Statistics for Windows, version 23.0 (IBM Corp., Armonk, N. Y., USA) software. All data were expressed as mean $\pm \mathrm{SD}$, median or in percentages as appropriate. Student's $t$-test was used for comparison of the means of variables among different groups. Multiple logistic regressions were used to see the influence of individual predictors on weight change. $\mathrm{P}$ value $\leq 0.05$ was considered to be statistically significant.

\section{Results}

In this study, a total of 93 newly diagnosed primary hypothyroid patients who completed the follow up were analyzed. The general characteristics of the study participants are given in Table 1. Their mean age was $35.85 \pm 11.57$ years, $71 \%$ of them were female and more than half $(64.5 \%)$ came from middle class family.

Table 1. Demographic characteristics of the study participants.

\begin{tabular}{lll}
\hline Characteristics & $\mathbf{N}=\mathbf{9 3}$ \\
\hline $\begin{array}{l}\text { Age (years, mean } \pm \text { SD) } \\
\text { Gender }\end{array}$ & & $35.85 \pm 11.57$ \\
& Male & $29 \%$ \\
Occupation & Female & $71 \%$ \\
& & \\
& Housewife & $49.5 \%$ \\
& Service & $18.5 \%$ \\
& Student & $10.5 \%$ \\
& Others & $21.5 \%$ \\
\hline
\end{tabular}




\begin{tabular}{lll}
\hline Characteristics & $\mathbf{N = 9 3}$ \\
\hline Socio-economic status & & \\
& Low & $35.5 \%$ \\
& Middle & $64.5 \%$ \\
& High & $0 \%$ \\
\hline
\end{tabular}

(Within parentheses are percentages over column total)

Table 2 shows the baseline and post-treatment body weight, BMI, TSH and FT4 of the participants. The posttreatment values of serum TSH $(85.1 \pm 51.6$ vs. $1.87 \pm 0.9$, mean \pm SD), body weight $(62.2 \pm 13.7$ vs. $59.0 \pm 12.1$, mean \pm SD) and BMI (25.1 \pm 4.6 vs. $23.8 \pm 4.1$, mean \pm SD) were significantly lower, and FT4 level $(0.49 \pm 019$ vs. $1.4 \pm 0.78$, mean $\pm \mathrm{SD}$ ) was significantly higher in comparison to their pretreatment values.

Table 2. Body weight, BMI, TSH and FT4 of study participants at baseline and post-treatment (N=93).

\begin{tabular}{|c|c|c|c|c|c|c|c|}
\hline \multirow{2}{*}{ Variables } & \multicolumn{3}{|l|}{ At baseline } & \multicolumn{3}{|c|}{ At follow-up (after $6 \pm 1$ weeks) } & \multirow{2}{*}{$p$} \\
\hline & Mean \pm SD & Median & Range & Mean \pm SD & Median & Range & \\
\hline $\mathrm{TSH}(\mu \mathrm{IU} / \mathrm{mL})$ & $85.1 \pm 51.6$ & 75.0 & $7.1-173.7$ & $1.87 \pm 0.9$ & 2.0 & $1.0-3.0$ & $<0.001$ \\
\hline Body weight $(\mathrm{Kg})$ & $62.2 \pm 13.7$ & 61.8 & $27.1-122.8$ & $59.0 \pm 12.1$ & 58.9 & 26.1-108.1 & $<0.001$ \\
\hline BMI $\left(\mathrm{Kg} / \mathrm{M}^{2}\right)$ & $25.1 \pm 4.6$ & 24.9 & $13.7-47.0$ & $23.8 \pm 4.1$ & 23.6 & $13.3-40.8$ & $<0.001$ \\
\hline
\end{tabular}

$p$-value by Student's $t$-test

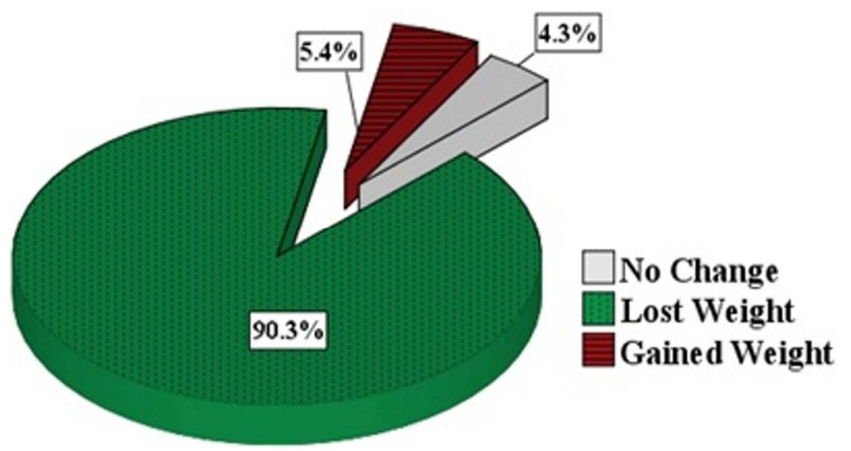

Figure 1. Frequencies of study population with varying categories of weight changes after levothyroxine treatment.
Figure 1 depicts the proportions of patients according to change in weight after levothyroxine treatment; $90.3 \%$ lost weight, $5.4 \%$ gained weight while $4.3 \%$ of patients didn't show any change in their pretreatment weight.

Mean changes in body weight and BMI at 6 week of LT4 replacement in study participants with different categories of baseline TSH is shown in table 3 . The mean change in body weight was $3.19 \pm 0.32 \mathrm{Kg}$ (mean $\pm \mathrm{SEM}$, median $2.8 \mathrm{Kg}$ ) and the mean BMI change was $1.31 \pm 0.14 \mathrm{Kg} / \mathrm{M}^{2}$ (mean $\pm \mathrm{SEM}$, median $1.04 \mathrm{Kg} / \mathrm{M}^{2}$ ). The mean changes in body weight and BMI did not significantly differ among subjects with different pretreatment TSH categories.

Table 3. Mean changes in body weight and BMI in study participants with different categories of baseline TSH at 6 week of LT4 replacement (N=93).

\begin{tabular}{|c|c|c|c|c|c|}
\hline & \multirow{2}{*}{$\begin{array}{l}\text { Total participants } \\
(\mathrm{N}=93)\end{array}$} & \multicolumn{3}{|l|}{ TSH subcategories } & \multirow{2}{*}{$p$} \\
\hline & & $<50 \mu \mathrm{IU} / \mathrm{mL}(\mathrm{N}=\mathbf{3 0})$ & $50-100 \mu I U / m L(N=29)$ & $>100 \mu \mathrm{IU} / \mathrm{mL}(\mathrm{N}=34)$ & \\
\hline Change in Body Weight (mean \pm SEM) & $3.19 \pm 0.32$ & $2.25 \pm 0.29$ & $3.85 \pm 0.64$ & $3.47 \pm 0.63$ & 0.115 \\
\hline Change in BMI (mean \pm SEM $)$ & $1.31 \pm 0.14$ & $0.89 \pm 0.12$ & $1.56 \pm 0.27$ & $1.48 \pm 0.30$ & 0.130 \\
\hline
\end{tabular}

$p$-value by Oneway ANOVA

Multivariate linear regression analysis of potential predictors of weight change is shown in table 4 . None of the variables at baseline influenced the change in weight independently.

Table 4. Multivariate linear regression analyses of potential predictors of weight change.

\begin{tabular}{lll}
\hline Variables & Beta-coefficient & $\boldsymbol{p}$ \\
\hline Age (years) & 0.022 & 0.843 \\
Gender & 0.230 & 0.158 \\
Socio-economic status & -0.019 & 0.865 \\
Weight at baseline & 0.157 & 0.226 \\
TSH at baseline $(\mu \mathrm{IU} / \mathrm{mL})$ & 0.030 & 0.836 \\
FT4 at baseline $(\mathrm{ng} / \mathrm{dL})$ & 0.003 & 0.985 \\
Thyroid autoimmunity & -0.036 & 0.747 \\
\hline
\end{tabular}

\section{Discussion}

This study evaluated the changes in body weight and
BMI 6 weeks after levothyroxine replacement in newly diagnosed primary hypothyroid patients. There were significant reductions of both mean body weight and BMI at 6 weeks of treatment. $90.3 \%$ of the patients lost weight, no change in weight was observed in $4.3 \%$ whereas $5.4 \%$ of patients gained weight in comparison to their baseline weight.

Primary hypothyroidism is usually associated with weight gain resulting from a reduction of basal metabolic rate (BMR), decreasing level of spontaneous physical activity level due to alteration of skeletal muscle metabolism and function, psychomotor slowing and impaired cardiac output, and accumulation of water-binding glycosaminoglycans which led to the term myxedema [8]. Reduced capacity of renal free-water excretion, increased antidiuretic hormone level, and increased protein extravasation to a decreased lymphatic drainage have also been described which also contribute to weight gain in 
hypothyroidism [9-11]. Treatment of hypothyroidism has been found to be associated with decreased body weight attributable to a decrease in lean mass because the total fat mass was largely unchanged and it is hypothesized that the weight loss often observed during such treatment is predominantly due to loss of excess body water accumulated during the state of myxedema [8].

Few works have been done evaluating the change in body weight following treatment with levothyroxine in newly diagnosed primary hypothyroid patients. In 1940, Plummer conducted such type of research on clinically diagnosed myxoedema patients and observed a significant loss of body weight after levothyroxine replacement [12]. The results of this study were similar to the results of another prospective study done by Karmisholt et al. who found significant weight loss following levothyroxine treatment, though the duration of the follow-up was longer (one year) [8]. In another study done by Hoogwerf et al., hypothyroid subjects showed a small decline in mean body weight over the first six months of treatment but returned to pretreatment weight by 24 months [13]. Lee et al. followed up 101 primary hypothyroid patients for the changes in body weight and BMI after levothyroxine replacement for 24 months; only $52 \%$ of patients lost weight, with a mean weight loss of $3.8 \pm 4.4 \mathrm{~kg}$. Weight change at a median of 5 months (range 1.1 to 25.6 months) was $-0.1 \mathrm{~kg}$ (range -20.6 to $7.7 \mathrm{~kg}$ ) and the median change in BMI was $-0.1 \mathrm{~kg} / \mathrm{m}^{2}$ (range -7.1 to $3.3 \mathrm{~kg} / \mathrm{m}^{2}$ ); both the changes in weight and BMI were statistically nonsignificant [14]. In another retrospective study done on children with acquired hypothyroidism by Lomenick et al., only $31 \%$ of 68 Patients experienced mean weight loss of 2.3 $\mathrm{kg}$ at follow-up of 4.4 months [15].

None of the age, gender, socio-economic status, weight at baseline, baseline TSH and FT4, and thyroid autoimmunity was found to be the significant predictor of changes in weight in this study; Lee et al. had similar observations [14].

The strengths of the study were its prospective in nature, a relatively large sample size including biochemically diagnosed overt hypothyroid patients and the use of rigorous exclusion criteria to exclude the conditions that might interfere with the treatment pattern or weight change or both. The limitations of included that the study was of short duration and failed to elucidate the persistence of weight loss at long-term follow up, lack of control group and the lack of bioavailability data of prescribed levothyroxine brand.

\section{Conclusion}

Though levothyroxine replacement was associated with a significant reduction of mean body weight and BMI, not all patients experienced weight loss in the current study. Prospective studies with long-term follow-up may be undertaken for the better understanding of the effect levothyroxine replacement on the change in body weight in the primary hypothyroid patients.

\section{References}

[1] D. S. Cooper and P. W. Ladenson, "The Thyroid Gland," in Greenspan's Basic \& Clinical Endocrinology, 9th Edition, D. G. Gardner and D. Shoback, Eds. New York: The McGrawHill Companies, 2007, pp. 163-226.

[2] Canaris, G. J., Manowitz, N. R., Mayor, G., \& Ridgway, E. C. (2000). The Colorado thyroid disease prevalence study. Arch Intern Med, 160, 526-34.

[3] Hollowell, J. G., Staehling, N. W., Flanders, W. D., Hannon, W. H., Gunter, E. W., Spencer, C. A., et al. (2002). Serum TSH, T (4), and thyroid antibodies in the United States population (1988 to 1994): National Health and Nutrition Examination Survey (NHANES III). J Clin Endocrinol Metab, 87, 489-99.

[4] Hoogendoorn, E. H., Hermus, A. R., de Vegt. F., Ross, H. A., Verbeek, A. L., Kiemency, L. A., et al. (2006) Thyroid function and prevalence of anti-thyroperoxidase antibodies in a population with borderline sufficient iodine intake: Influences of age and sex. Clin Chem, 52, 104-11.

[5] Unnikrishnan, A. G., Kalra, S., Sahay, R. K., Bantwal, G., John, M., \& Tewari, N. (2013). Prevalence of hypothyroidism in adults: An epidemiological study in eight cities of India. Indian J Endocr Metab, 17, 647-52.

[6] Fish, L. H., Schwartz, H. L., Cavanaugh, J., Steffes, M. W., Bantle, J. P., \& Oppenheimer, J. H. (1987). Replacement dose, metabolism, and bioavailability of levothyroxine in the treatment of hypothyroidism. Role of triiodothyronine in pituitary feedback in humans. N Engl J Med, 316, 764-70.

[7] Roos, A., Linn-Rasker, S. P., van Domburg, R. T., Tijssen, J. P., \& Berghout, A. (2005). The Starting Dose of Levothyroxine in Primary Hypothyroidism Treatment. A Prospective, Randomized, Double-blind. Arch Intern Med, 2005, 165, 1714-20.

[8] Karmisholt, J., Andersen, S., \& Laurberg, P. (2011). Weight loss after therapy of hypothyroidism is mainly caused by excretion of excess body water associated with myxoedema. J Clin Endocrinol Metab, 2011, 96, E99-103.

[9] Sahu'n, M., Villabona, C., Rosel, P., Navarro, M. A., Ramo'n, J. M., Go'mez, J. M., \& Soler, J. (2001). Water metabolism disturbances at different stages of primary thyroid failure. J Endocrinol, 168, 435-45.

[10] Park, C. W., Shin, Y. S., Ahn, S. J., Kim, S. Y., Choi, E. J., Chang, Y. S., \& Bang, B. K. (2001). Thyroxine treatment induces upregulation of renin-angiotensin-aldosterone system due to decreasing effective plasma volume in patients with primary myxoedema. Nephrol Dial Transplant, 16, 1799-806.

[11] Parving, H. H., Hansen, J. M., Nielsen, S. L., Rossing, N., Munck, O., \& Lassen, N. A. (1979). Mechanisms of edema formation in myxedema: increased protein extravasation and relatively slow lymphatic drainage. N Engl J Med, 301, 460-5.

[12] Plummer, W. A. (1940). Body weight in spontaneous myxedema. Trans Am Assoc Study Goiter, 88-98.

[13] Hoogwerf, B. J., \& Nuttall, F. Q. (1984). Long-term weight regulation in treated hyperthyroid and hypothyroid subjects. Am J Med, 76, 963-70. 
[14] Lee, S. Y., Braverman, L. E., \& Pearce, E. N. (2014). Changes in body weight after treatment of primary hypothyroidism with levothyroxine. Endocr Pract, 20, 1122-8.
[15] Lomenick, J. P., El-Sayyid, M., \& Smith, W. J. (2008). Effect of levo-thyroxine treatment on weight and body mass index in children with acquired hypothyroidism. J Pediatr, 152, 96-100. 